\title{
Fish Originated Bacterial Zoonoses
}

\author{
Filiz Ozcan (Corresponding author) \\ Department of Fisheries and Diseases, Faculty of Veterinary Medicine, \\ University of Dicle, 21280, Diyarbakir, Turkey \\ E-mail: felizozcan@gmail.com; filiz.ozcan@dicle.edu.tr \\ Neval Berrin Arserim \\ Department of Microbiology, Faculty of Veterinary Medicine, \\ University of Dicle, 21280, Diyarbakir, Turkey \\ E-mail: nevalb@dicle.edu.tr
}

\begin{abstract}
Zoonotic diseases are diseases that are transmitted from animals to humans and from humans to animals. Zoonotic bacterial infections are an important public health problem in the world. Zoonotic infections from fish can cause problems for fish producers and consumers. Fish diseases are important in terms of economic losses they cause, adversely affect exports, residue problems of unconscious drugs, environmental pollution and increase antibiotic resistance, and some of the diseases are zoonotic. In this review, potential bacterial fish zoonoses are summarized according to the information obtained from publications.
\end{abstract}

Keywords: Fish, Bacterial Zoonoses, Fish Diseases, Zoonoses, Bacteria

DOI: $10.7176 / \mathrm{JSTR} / 6-12-03$

\section{Balık Orjinli Bakteriyel Zoonozlar}

Özet

Zoonoz hastalıklar hayvanlardan insanlara insanlardan hayvanlara bulaşan hastalıklardır. Zoonotik bakteriyel enfeksiyonlar dünyada önemli bir halk sağlığı problemidir. Balıklardan geçen zoonotik enfeksiyonlar balık üretici ve tüketicilerinde problemlere sebep olabilir. Balık hastalıkları neden oldukları ekonomik kayıplar, ihracatı olumsuz yönde etkilemeleri, bilinçsiz kullanılan ilaçların kalıntı sorunu, çevre kirliliği oluşturmaları ve antibiyotik direncini arttırmaları ve hastalıkların bir kısmının zoonoz özellikte olması açısından önemlidir. Bu derlemede potansiyel bakteriyel balık zoonozlar yayınlarda elde edilen bilgiler doğrultusunda özetlenmiştir.

Anahtar Kelimeler: Balık, Bakteriyel Zoonozlar, Balık Hastalıkları, Zoonoz, Bakteri

\section{Giriş}

Dünyada uluslararası gıda ticaretinin giderek artması, tarımsal üretim teknikleri ile gıda üretim ve işleme teknolojilerindeki değişimler, iklim değişiklikleri, hızlı nüfus artı̧̧, turizmin artması, kırsal alanlardan kentlere göçün artması, insanların yaşam tarzı ve beslenme alışanlıklarındaki demografik değişimler, bağışıklık sistemi sorunlarına iliş̧in olarak toplumlarda hastalıklara duyarlı bireylerin sayısının artması, mikrobiyel adaptasyon ve antimikrobiyel direnç gibi faktörler gıda kaynaklı patojenlerin epidemiyolojisinde de önemli değişikliklerin ortaya çıkmasına neden olmuştur. Bu tablo küresel düzeyde yeni ve yeniden önem kazanan canlı ve gıda kaynaklı enfeksiyon ve zehirlenmelerin görülme sıklı̆̆ında önemli düzeyde artışa neden olmuştur [7,17,35].

Birçok enfeksiyon hastalığı hayvanlardan insanlara, insanlardan hayvanlara geçmekte olup bu tip hastalıklara da zoonoz adı verilmektedir. Balıklardan insanlara geçen enfeksiyonlar da Ichtyozoonoz (balık zoonozları) olarak bilinmektedir $[4,36]$ Bu hastalıkların oluşumunda çoğu zaman gıda maddeleri rol oynamakta, bulaşma en etkili yol olan ağız yoluyla gerçekleşmektedir [49]. 
Son zamanlarda balıktan insana geçen zoonozların sayısında ve dolayısı ile literatür incelemelerinde bir artış olmuştur; bu durum balık zoonozlarının her geçen gün biraz daha önem kazandığının bir belirtisi olarak göze çarpmaktadır [1,4]. Su canlılarında zoonotik hastalıklar dört kategoriye ayrılır; bakteriyel, paraziter, viral ve fungal. Bakteriyel enfeksiyonlar, temas yoluyla insanlara balıklardan bulaşan birincil zoonozlardır $[8,12,20,32]$. Balık zoonozu olarak düşünülen birçok bakteri genellikle fakültatif patojenlerdir ve sıklkkla ortak enfeksiyon ya da kesin zoonoz olduğu arasında bir ayrım yapmak mümkün değildir [19].

\section{Bakteriyel Balık Zoonozları}

Genellikle ciddi bakteriyel balık zoonozlarına daha çok Gram negatif bakteriler sebep olmaktadır. Gram pozitif bakterilerden ise sadece bir kısmı insanlarda hastalık oluşturucu etkiye sahiptir [36]. Balık bakteriyel zoonoz etkenleri Auistin ve Auistin (1999) [1] tarafindan şu şekilde bildirilmektedir;

* Aeromonas hydrophila (Diyare ve septisemiye)

* Campylobacter jejuni (gastroenterit)

* Clostridium botulinium tip E (botulismus)

* Edwardsiella tarda (diyare)

* Eryspelothrix rhusiopathiae (balık gülü)

* Leptospira interrogans (leptospiroz)

* Mycobacterium fortuitum(Atipik Mycobacteriosis)

* Pseudomanas aeroginosa (yara infeksiyonları)

* Plesiomonas shigelloides (gastroenterit)

* Pseudomonas fluorescens (yara infeksiyonları)

* Salmonella (besin zehirlenmesi)

* Streptecoccus inia (Mad Balık hastalığı)

* Vibrio parahaemolyticus (gastroenterit)

* Vibrio vulnificus (septisemi, yara infeksiyonları)

\section{Gram Pozitif Bakteriler}

3.1.Streptococcus spp.: Streptokoklar, Gram pozitif, hareketsiz, sporsuz, kapsülsüz ve aerobik mikroorganizmalardır [3]. Balıklardaki enfeksiyonlar genel olarak Lancefield grup B organizmaları (Streptococcus agalactiae) ya da Lancefield antijenlerini eksprese etmeyen Streptococcus iniae türlerinden kaynaklanmaktadır [19] Streptococcus iniae hem tatlı su hem de deniz balıklarında yaygın olmakla birlikte [23] akvaryum balıklarında çok sık rapor edilmemektedir [30]. Weinstein ve ark., 1997 [54] Toronto'da bir hastalık salgınında S. iniae' yı zoonoz enfeksiyon olarak identifiye etmişlerdir. Bu vakada dokuz hastada çiğ balık ile temasa bağlı olarak ortaya çıkan selülitis, bir hastada ayrıca endokarditis, meningitis ve artiritis saptanmıştır.

3.2. Clostridium spp.: Anaerop sporlu bir bakteri olan Clostridium cinsi üyeleri tatlı su ve deniz balıklarının intestinal sistemlerinde kommensal organizma olarak bulunmaktadır. Bazı türleri toksin oluşturur ve toksinleri insanlarda hastalık yapıcı etkiye sahiptir. Bu bakteri, kontaminasyon neticesinde, balıkların yüzeyinden de izole edilmektedir [36,46]. Clostridium türleri, insanlarda ciddi infeksiyonlarına sebep olmaktadır. Özellikle Clostridium perfringens ve Clostridium botulinum kontamine balıkların tüketilmesi sonucunda hastalık oluşturan iki önemli türdür [48] C. botulinum tüm dünyada tatlı su ve deniz balıklarının bağırsaklarında kommensal olarak bulunan, aynı zamanda çevresel sedimentlerde ve çürüyen organik maddelerde de bulunabilen bir mikroorganizmadır [19]. $C$. botulinum suşları serolojik olarak yedi farklı nörotoksin (A-G) üretmektedir. Bu toksin tipleri arasından insanlardaki salgınlarda en fazla karşlaşılan toksin tipleri tip A, B, E ve F iken, tip C ve D hayvanlardaki botulizm ile ilişkilendirilmektedir [14]. Balık tüketimiyle ilişkili olarak insanlarda ortaya çıkan birçok hastalık vakasından ise tip E toksininin sorumlu olduğu bildirilmektedir [19]. C. botulinum neurotoksin tip E'nin neden olduğu hastalık tablosu Amerika, Britanya ve Danimarka'da yetiştiriciliği yapılan salmonid balıklarda bildirilmiştir [16]. Bununla birlikte son yıllarda Güneydoğu Amerika'da kanal yayın balıklarında (Ictalurus punctatus) saptanan bir hastalık vakası viseral toksikozis olarak rapor edilmiştir [26]. Yapılan çalışmalar C. botulinum'un balıkların bağırsaklarında, yüzeylerinde, balık çiftliklerindeki sedimentlerde, balık ürünlerinde ve alglerde bulunabildiğini göstermektedir [55]

21 I P a g e 
3.3. Erysipelothrix spp.: Erysipelothrix türleri arasında E. rhusiopathiae, E. tonsillarum ve E. inopinata bulunmaktadır. Hayvanlarda E. rhusiopathiae'nın sebep olduğu hastalık "erysipelas" olarak bilinirken insanlarda hastalık "erysipeloid" olarak adlandırılmaktadır [19]. E. rhusiopathiae insanda, kuşlarda, koyunda ve domuzda ve diğer türlerde hastalığa sebep olabilir. Bu etken infekte olan insanda, parmaklarda ve bilekte kaşınma ve yanmaya sebep verir. Ayrıca hastalarda ödem, septisemi, endokardit, anemi ve menenjit de görülebilir [4,36]. E. rhusiopathiae küçük, Gram pozitif, çomak şeklinde, fakültatif aerobik, hareketsiz, spor oluşturmayan bir bakteridir [53,54] İnsanlara $E$. rhusiopatiae kaynaklı zoonotik bulaşmanın (fish-handlers disease) balıkçıllk sektöründe çalışanlar arasında meydana geldiği bildirilmektedir. Özellikle balıkçılara ve balık işleme fabrikalarındaki işçilere zarar veren bir meslek hastalığıdır. Deride lokalize infeksiyonu, parmaklar veya ellere yerleşerek enfeksiyon oluşturması (Balık gülü) ve septisemi olmak üzere üç değişik klinik formda görülebilir.

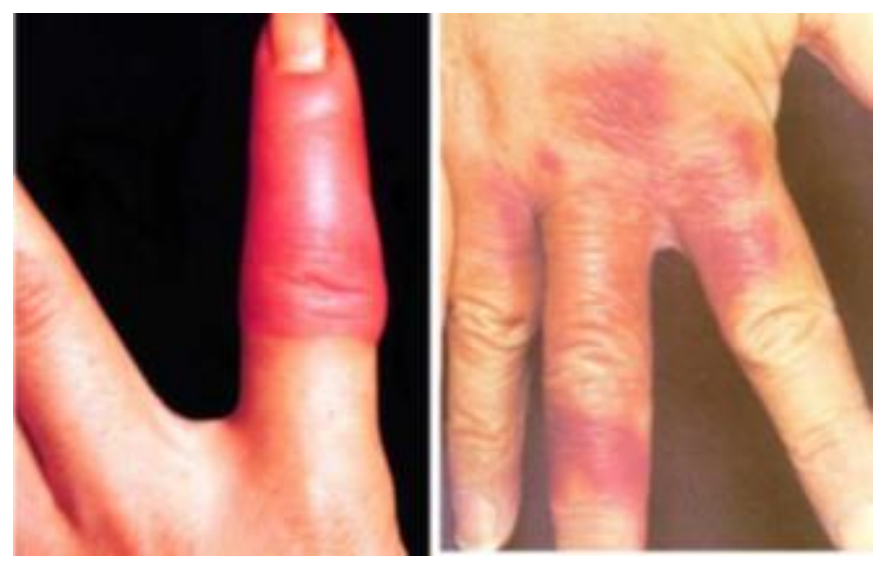

Erysipelothrix rhusiopathiae.

Sol parmaklarda ve elde morumsu kırmızı, sertleşmiş deri lezyonları [21]

3.4. Lactococcus garvieae: L. garvieae fakültatif anaerobik, hareketsiz, sporsuz, Gram pozitif oval kok şeklinde mikroorganizmalardır. Balıklarda L. garvieae tarafindan meydana getirilen laktokokkozis enfeksiyonu, özellikle, tatlı su kültürlerindeki salmonid balıklar ve denizde yetiştiriciliği yapılan balık türlerinde yıkımlayıcı bir etkiye sahip olan bir tür streptokokkozis enfeksiyonu olarak tanımlanmaktadır [57] Etken aynı zamanda ineklerdeki subklinik meme içi enfeksiyonlardan, mandalarda subklinik mastitisten, tavuk etlerinden, çiğ inek sütünden, et ürünlerinden, domuz kanı işleyen endüstriyel mezbahanelerden ve kedi ve köpeklerin tonsillerinden izole edilmiştir [57]. Son y1llarda ise endocarditis, kolesistit ve diskospondilitis'e neden olan bir insan patojeni olarak tanımlanmaktadır [19]. İnsanlarda görülen enfeksiyonlar ile akuakülterde görülen salgınlar arasındaki ilişki açı bir şekilde ortaya konulamasada, L. garvieae kaynaklı insan enfeksiyonları çiğ deniz ürünlerinin tüketilmesi ile ilişkilendirilmektedir.

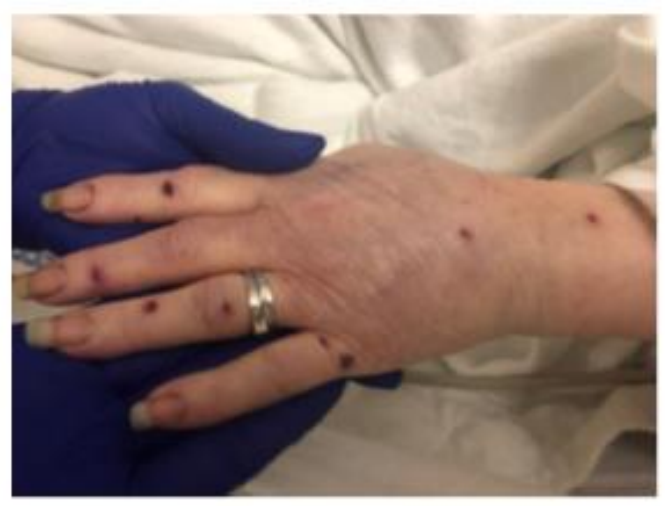

Lactococcus garvieae enfeksiyonu

Sonucu enfektif endokarditis [52]

22 | P a g e 
3.5. Nocardia spp.: Nocardia etkenleri Gram pozitif, zayıf asidorezistans özellikte aerobik, sporsuz, kokoid ve/veya küçük çomakçık şeklinde görülen mikroorganizmalardır [2]. Doğada yaygın olarak bulunan Nocardia türleri, insanlarda pulmoner, kutanöz, merkezi sinir sistemi ve sistemik nokardiyoz gibi çeşitli enfeksiyonlara neden olabilmektedir [28,56]. İnsanlarda Nocardia spp. enfeksiyonları öncelikli olarak Nocardia asteroides ve yakın akraba türleri Nocardia farcinica, Nocardia brasiliensis ve Nocardia otitidiscaviarum ile ilişkilendirilmesine rağmen [28] balık ve insan arasında henüz epidemiyolojik veya genetik bir ilişki saptanamadığı bildirilmiştir [19].

\section{Gram Negatif Bakteriler}

4.1. Vibrio spp.: Vibrio türleri deniz ortamında çok yaygın bulunmaktadır [44]. Vibrionaceae familyası içerisinde yer alan Vibriolar Gram negatif, fakültatif anaerobik, genellikle hareketli, düz veya hafif kıvrık çomakcıklar şeklinde mikroorganizmalardır [3]. Vibrio türleri balıklarda ve sucul ortamda yaygın bir dağılım göstermektedir. İnsan enfeksiyonlarıyla ilişkili türler Vibrio vulnificus, Vibrio parahaemolyticus, Vibrio cholerae [2] ve Vibrio damsela 'dır [20]. Bu bakterilerin içerisinde Vibrio vulnificus, balıklardan insanlara bulaşan en yaygın olan Vibrio türüdür [32]. Bu etkenden kaynaklanan hastalığın belirtileri ateş, hafıza kaybı, ekimotik hemerojiler ve ekstremitelerde ağrılardır [36] Aynı zamanda hastalık ödem, hemoraji ve ekstensif doku nekrozu ile karakterizedir [10,36]. İnsanlar da Vibrio vulnificus enfeksiyonu genellikle balık, kabuklu deniz ürünleri tüketimi ve deniz suyu kontaminasyonu ile ilişkilendirilmektedir. Ancak enfeksiyon, açık yaralarla temastan da kaynaklanabilir [8] ve bu enfeksiyonların yaklaşı \%25'inin açık yaranın bakterileri içeren deniz suyuna doğrudan maruz kalmasından kaynaklandığı bildirilmektedir [9]. Tipik olarak, yüzme ve balık tutma gibi su aktiviteleri bireyleri bakterilere maruz bırakır, ancak denizdeki vahşi yaşamla ilişkilendirilmiştir [9]. Vibrio vulnificus kısa inkübasyon sürelerine sahiptir [11] ve çoğu semptom 24 saat sonra ortaya çıkar [38].

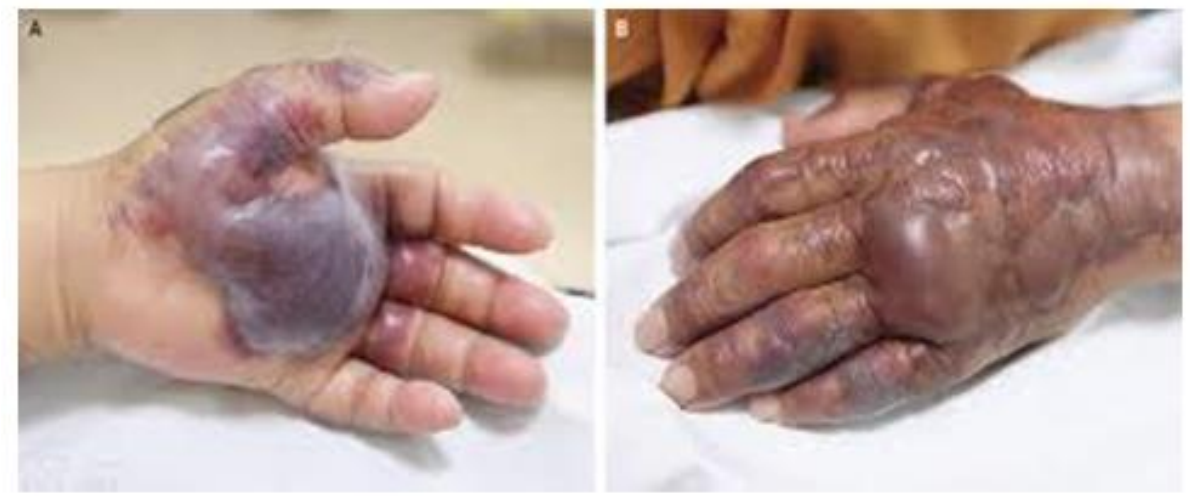

Vibrio vulnificus enfeksiyonu sonucu oluşan deri lezyonları [25]

4.2.Edwersiella spp.: Edwardsiella cinsleri Enterobacteriaceae familyasının bir üyesidir ve bu cins içerisinde yer alan türler Gram negatif, genellikle hareketli, fakültatif anaerobik mikroorganizmalardır [42]. Edwarsiella ictaluri, Edwarsiella tarda ve Edwarsiella hoshinae balı, insan, kuş ve sürüngenlerden izole edilmiş türler [19;34] Bu bakterilerin içerisinde Edwarsiella tarda insanda hastalığa neden olmaktadır. Bu tür aynı zamanda yayın balıklarında hastalık etkeni olup kuşlar, kurbağalar, balıklar ve diğer türlerin barsak mikroflorasında bulunmaktadır [36] Enfekte balık ve kontamine sular enfeksiyon kaynağıdır. Edwersiella tarda'nın tropikal akvaryum balıklarından olan melek balığından (Pterophyllum scalere) küçük bir çocuğa bulaşarak ishale sebep olduğu bildirilmiştir [1]. E. tarda'nın neden olduğu insan enfeksiyonları primer olarak gastroenteritis ile karakterizedir. Bununla birlikte septisemi ve menenjit gibi sistemik hastalıklar ve yara enfeksiyonları da görülmektedir [13, 22]. E. tarda asemptomatik olarak insanların dışkısında bulunabilmektedir [22]. 

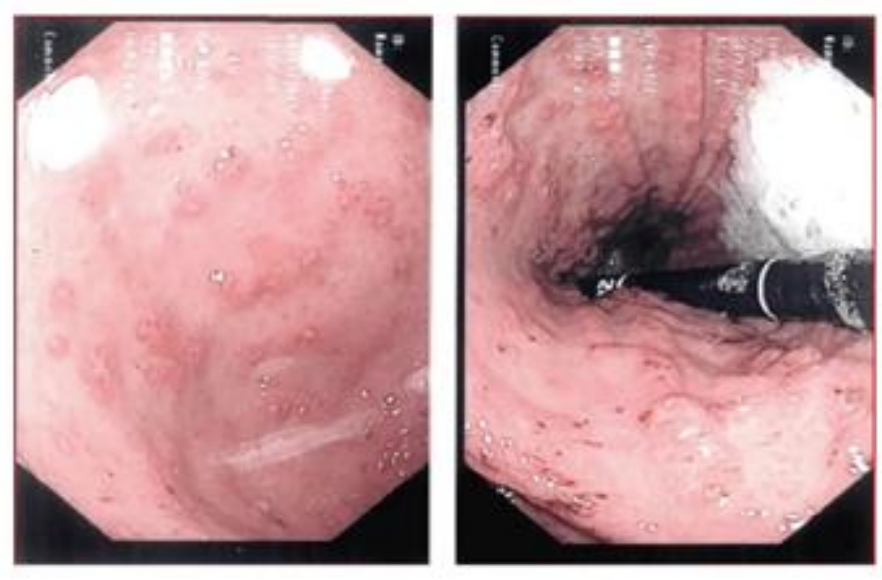

Edwersiella tarda enfeksiyonu sonucu oluşan midede çoklu aftöz ülserasyon ve nodülerlik (Üst Mide Endoskopi Görüntüsü) [31]

4.3. Aeromonas sp.: Aeromonas'lar akuatik çevrenin normal faunasında bulunan fakültatif anaerobik, oksidaz pozitif, Gram negatif bakterilerdir. Hareketli (Aeromonas hydrophila, Aeromonas sobria, Aeromonas.caviae vb.) ve hareketsiz (Aeromonas salmonicida, Aeromonas achromogenes, Aeromonas masoucida) olmak üzere iki guruba ayrılırlar. Hareketsiz türler insan patojeni olarak pek önem arz etmemektedir [48]. İnsanlarda hastalık oluşturan aeromonaslar septisemi, yara enfeksiyonu, menenjit, peritonit ve karaciğer fonksiyon bozukluğu gibi çok değişik enfeksiyonlar ile ortaya çıkabilmektedir. Özellikle bakteriyel gastroenterit, septisemi, peritonit, hemolitik üremik sendrom ve solunum yolu hastalıkları gibi enfeksiyonlara neden olabilmektedir [27] Aeromonas hydrophila kaynaklı hastalıkların büyük bir kısmı su ürünleri veya uzun süreli dondurulmuş tüketime hazır gıdalar ile ilişkilendirilmektedir [15]. Bununla birlikte hastalık etkenlerinin direkt olarak canlı balıklardan insanlara geçişi ile ilgili bilgiler sınırlıdır.

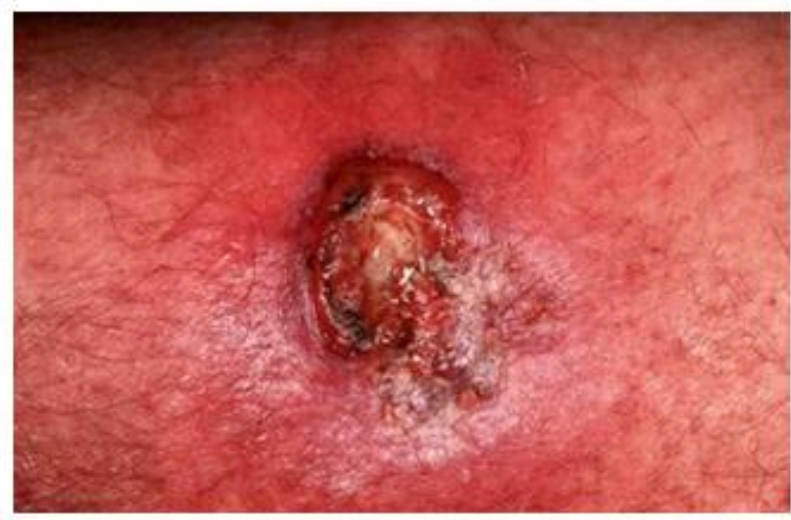

Aeromonas hydrophila'nın neden olduğu

bir balıkçının ön bacağında travmaya bağlı nekrotik ülser [33]

4.4. Pseudomonas sp. : Pseudomonas'lar Gram negatif aerob çomaklar olup, bir kısmı pigment üretirken bir k1smı da toksin üretmektedirler [5] Bu mikroorganizmalar tüm dünyada su ve toprakta yaygın olarak bulunurlar [19]. Pseudomonas aeruginosa insanlarda pnömoni etkeni olarak bilinmektedir ve balıkların viseral dokularından izole edilmiştir [29]. Pseudomonas fluorescens' in de insanlarda kistik fibrozis vakalarından izole edildiğine dair veriler bulunmaktadır [47].

4.5. Plesiomonas shigelloides : Plesiomonas shigelloides Gram negatif, hareketli ve oksidaz pozitif uzun çomak şeklinde mikroorganizmalardır [50] Dünyada yaygın bir dağılıma sahiptir. Başlıca tatlı sularda (havuz, akarsu ve göller) bulunmasına rağmen dere ağzı ve deniz ortamında da bulunmaktadır. $P$. shigelloides çeşitli balık türlerinden, deniz kabuklularından, kuşlardan ve insanlardan izole 
edilmiştir. P. shigelloides enfeksiyonu büyük çoğunlukla yaz aylarında meydana gelir [39]. İnsanlarda başlıca intestinal hastalıklar olmak üzere yüksek mortalite oranı ile seyreden sepsis ve menengitis gibi daha yaygın görülen ekstraintestinal hastalıklara neden olan önemli bir patojendir [50]. İnsanlardan rapor edilen enfeksiyon vakalarının büyük çoğunluğunun başlıca az pişmiş ya da çiğ istiridye, balık, deniz tarağı ve karides gibi kontamine deniz ürünlerinin alımı ile veya içerisinde Plesiomonas bulunan içilebilir sulardan kaynaklandığı düşünülmektedir [22]

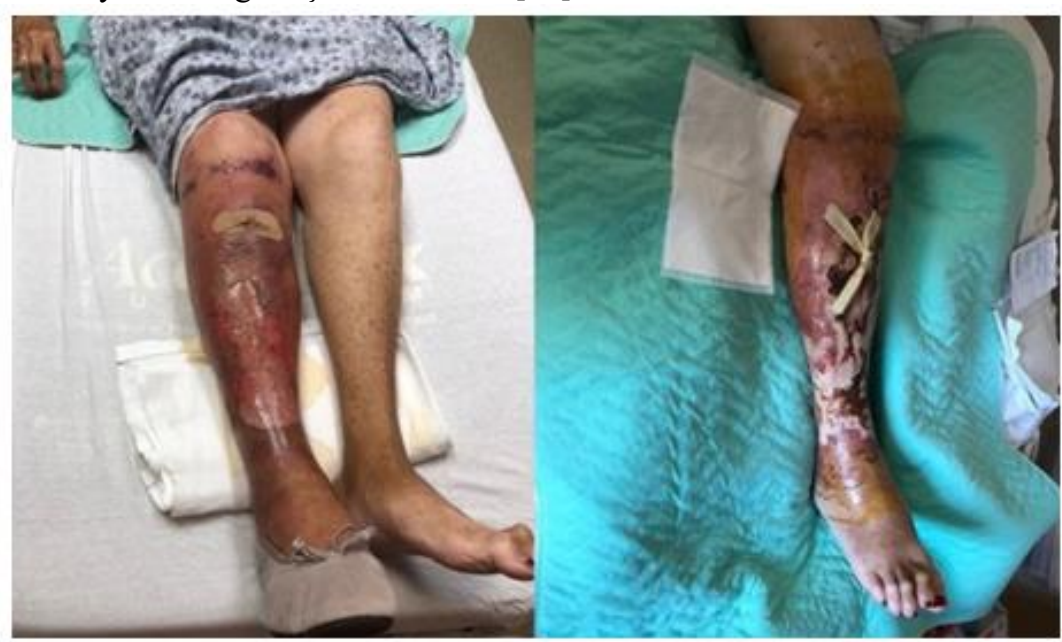

\section{Plesiomonas shigelloides enfeksiyonu [40]}

4.6. Mycobacterium spp Mycobacterium enfeksiyonları, balıklar tarafindan bulaşan en yaygın bakteriyel enfeksiyonlar arasındadır $[8,19,43,51] \mathrm{Su}$ ürünleri yetiştiriciliğinde tanklarda ve akvaryumlarda çalışan kişileri daha çok etkilemektedir [12,37] Mycobacterium cinsi bakteriler hareketsiz, aside dirençli boyanan çomaklardır. Balık patojeni olarak üç türü tanımlanmıştır. Bunlardan Mycobacterium fortuitum, tropical ve 1 lık iklimde bulunur ve çeşitli balıklarda hastalık oluşturur. M.chelonei türü salmonidlerden izole edilmişltir. M.marinum, M. fortuitum hasta balıklardan insanlara geçebilen türlerdir $[1,18,36]$ Özellikle yüzme havuzlarında, akvaryum duvarlarında ve süs balıklarında çok bulunan bu bakteriler insanlara derideki yaralardan bulaşıp, granüloma infeksiyonu oluştururlar. Lezyonlar, el ve ayaklarda önce mavi morumsu renkte, sonra granülomatöz ülser biçiminde gelişir [6].

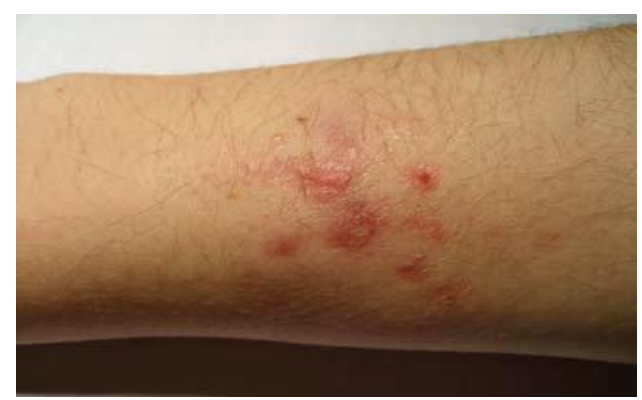

Balık tanklarında çalışan bir işçinin kolundaki Mycobacterium marinum enfeksiyonu [41]

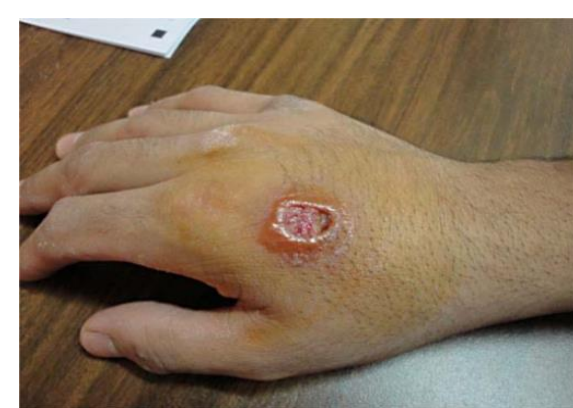

Mycobacterium marinum enfeksiyonu teşhisi konulan sağ elinde kronik ülser oluşmuş, 35 yaşında bir erkek [45]

\section{Referanslar}

[1] Auistin B., Auistin D.A. (1999) Bacterial Fish Pathogens Disease of Farmed and Wild Fish. 457.

[2] Austin, B. (2010) Vibrios as causal agents of zoonoses. Veterinary Microbiology 140: 310-317. 
[3] Arda M., Seçer S., Sarıyyüpoğlu M. (2005) Balık Hastalıkları. II. Baskı (Genişletilmiş). Ankara: Medisan Yayın Serisi: 61. p.70, 96, 99, 105.

[4] Babu, S.P. (2000) Icthyozoonoses, Reviews fish disease and infections transmissable to man, including some unfamiliar and recently recognized fish-borne maladies. Fish Farmer 14: 14.

[5] Bergan ,T. (1981) Human and Animal Pathogenic Members of the Genus Pseudomonas "Starr, M.P., H. Stolp, H.G. Trüber, A. Balows, und H.G. Schelegel (Ed.) The Prokaryotes" Vol. II, Springer Verlag, Berlin

[6] Bilgehan, H. (1995) Klinik Mikrobiyolojide Tanı, Barış Yayınları.

[7] Bliven., KA, Maurelli., AT. (2016) Evolution of bacterial pathogens within the human host. Microbiol Spectr, 4(1)- DOI:10.1128/microbiolspec.VMBF-0017.

[8] Boylan, S. (2011) Zoonoses associated with fish. Veterinary Clinics of North America: Exotic Animal Practice 14:427-438.

[9] Bross, M. H., Soch, K., Morales, R., Mitchell, R. B. (2007) Vibrio vulnificus: diagnosis and treatment. American Family Physician 76: 539-544.

[10] Cann, DC., Taylor, LY. (1982). An outbreak of botulism in rainbow trout, Salmo gairdneri Richardson, farmed in Britain. J Fish Dis. 5, 393-399.

[11] Chiang, S.R., Chuang, Y.C. (2003) Vibrio vulnificus infection: clinical manifestations, pathogenesis, and antimicrobial therapy. Journal of Microbiology, Immunology and Infection 36: $81-88$.

[12] Chomel, B. (2015) Diseases Transmitted by Less Common House Pets. Microbiology Spectrum 3(6):IOL5-0012-2015. doi:10.1128/microbiolspec.IOL5-0012.

[13] Clarridge, JE., Musher, DM., Fainstein ,V., Wallace, RJJr (1980). Extraintestinal human infection caused by Edwardsiella tarda. J Clin Microbiol. 11, 511-514.

[14] Collins, MD., East, AK, (1998). Phylogeny and taxonomy of the foodborne pathogen Clostridium botulinum and its neurotoxins. J Appl Microbiol. 84, 5-17.

[15] Daskalov H, (2006). The importance of Aeromonas hydrophila in food safety. Food Control. 17(6), 474-483.

[16] Eklund, MW., Poysky, FT., Peterson, ME., Peck, LW., Brunson, WD., (1984). Type E botulism in salmonids and conditions contributing to outbreaks. Aquaculture. 41, 293-309.

[17] Erol, I (2012). Monitoring and surveillance: epidemiology of foodborne pathogens and food safety. 499-530. In: Yan, X, Juneja, V. K, Fratamico, P. M, Smith, J. L. (Eds). Omics, microbial modelling and technologies for foodborne pathogens. DEStech Publications, Pennsylvania, USA.

[18] Frerichs G.N., Roberts R.J. (1989) Bacteriology of Teleost. Fish Pathology. Second Edition Baillicre Tindal, London, 289.

[19] Gauthier, DT. (2015). Bacterial zoonoses of fishes: a review and appraisal of evidence for linkages between fish and human infections. Vet J. 203(1), 27-35. 
[20] Haenen, O.L.M., Evans, J.J., Berthe, F. (2013) Bacterial infections from aquatic species: Potential for and prevention of contact zoonoses. Revue Scientifique et Technique de L'Office International des Epizooties 32:497-507.

[21] Harper, K.J and Erickson, K. (2016). Marine Zoonotic Diseases and You, Masna Educational Series http://masna.org/masna-education/zoonotic-diseases/

[22] Janda JM, Abbott SL, (1993). Infections associated with the genus Edwardsiella: the role of Edwardsiella tarda in human disease. Clin Infect Dis. 17, 742-748.

[23] Janda, JM., Abbott SL. (1999). Unusual food-borne pathogens. Listeria monocytogenes, Aeromonas, Plesiomonas, and Edwardsiella species. Clin Lab Med. 19, 553-582.

[24] Janda JM, Abbott SL, (2010). The genus Aeromonas: Taxonomy, pathogenicity, and infection. Clin Microbiol Rev. 23, 35-73.

[25] Jin Park, M.D. and Chang-Seop Lee, M.D. (2018) Vibrio vulnificus infection, N Engl J Med 2018; 379:375 DOI: 10.1056/NEJMicm1716464.[

[26] Khoo, LH., Goodwin, AE., Wise DJ., Holmes WE., Hanson LA., Steadman JM., Mc Intyre LM., Gaunt PS., (2011). The pathology associated with visceral toxicosis of catfish. J Vet Diagn Invest. 23(6), 1217-1221.

[27] Lau SM., Peng MY., Chang FY (2000) Outcomes of Aeromonas bacteremia in patients with different types of underlying disease. J Microbiol Immunol Infect. 33:241e7.

[28] Lederman, ER., Crum NF. (2004). A case series and focused review of nocardiosis. Medicine. $83,300-313$.

[29] Leung, CK., Huang, YW., Pancorbo, OC. (1992). Bacterial pathogens and indicators in catfish and pond environments. J Food Protect. 55, 424-427.

[30] Lewbart, G.A. (2001) Bacteria and ornamental fish. Seminars in Avian and Exotic Pet Medicine 10(1): 48-56.

[31] Li, A.K., Barton, M., Delport, J.A. and Ashok, D (2019) Edwardsiella tarda Infection Triggering Acute Relapse in Pediatric Crohn's Disease Case Reports in Infectious Diseases Volume 2019, Article ID 2094372, 3 pages https://doi.org/10.1155/2019/2094372

[32] Lowry, T., Smith, S.A. (2007) Aquatic zoonoses associated with food, bait, ornamental, and tropical fish. Journal of the American Veterinary Medical Association 231:876-880.

[33] Menno T.W. Gaastra, Book Editor(s): William R. Faber MD, PhD Roderick J. Hay DM, FRCP, FRCPath Bernard Naafs MD, PhD First published: 10 January (2012). Aquatic Skin Disorders https://doi.org/10.1002/9781118472620.ch24

[34] Mohanty BR, Sahoo PK. (2007). Edwardsiellosis in fish: a brief review. J Biosci. 32, 1331134

[35] Murphy., CP, Fajt., VR, Scott., HM, Foster., MJ, Wickwıre., P, Mcewen, SA (2016): Scoping review to identify potential non-antimicrobial interventions to mitigate antimicrobial resistance in commensal enteric bacteria in North American cattle production systems. Epidemiol Infect, $144,1-18$.

[36] NemetzT.G, Shotts E.B. Jr: Zoonotic Disease Chapter 17. (1993). "Stroskopfmle(Ed): Fish Medicine" p.214,W.B. Saunders Company. Philadelphia, London,

27 | P a g e

www.iiste.org 
[37] Novotny L., Dvorska L., Lorencova A., Beran V., Pavlik I. (2004) Fish: a potential source of bacterial pathogens for human beings. Veterinární medicína 49(9): 343-358.

[38] Oliver, J. D. (2005) Wound infections caused by Vibrio vulnificus and other marine bacteria. Epidemiology and Infection 133(3): 383-391.

[39] Pence MA, (2016). Wound infection with Plesiomonas shigelloides following a freshwater injury. J. Clin Microbiol. 54(5), 1180-1182.

[40] Pennycook, K.M., Pennycook, K.B., Cready, T. Mcc; Kazanowski, D. (2020) Severe cellulitis and bacteremia caused by Plesiomonas shigelloides following a traumatic freshwater injury, IDCases Volume 19, 2020, e00637 https://doi.org/10.1016/j.idcr.2019.e00637

[41] Piersimoni, C., Scarparo, C. (2009) Extrapulmonary Infections Associated with Nontuberculous Mycobacteria in Immunocompetent Persons. Emerging Infectious Diseases 15(9): 1351-1358.

[42] Plumb JA, (1999). Edwardsiella Septicemias. In: Fish Diseases and Disorders Volume 3. Viral, Bacterial and Fungal İnfections. Ed.: P.T.K. Woo, D.W. Bruno, CAB International, New York, USA. p.479-521.

[43] Prearo, M., Zanoni, R. G., Campo Dall’Orto, B., Pavoletti, E., Florio, D., Penati, V., Ghittino, C. (2004) Mycobacterioses: emerging pathologies in aquarium fish. Veterinary Research Communications 28:315-317.

[44] Roberts, H.E., Palmeiro, B., Weber, E.S 3rd. (2009) Bacterial and Parasitic Diseases of Pet Fish. Veterinary Clinics of North America: Exotic Animal Practice 12(3):609-638.

[45] Salik, D., Del Marmol, V. (2011) Refractory Hand Ulceration: A Case of Chronic Ulceration and Sporotrichoid Spread in a Fish Tank Hobbyist following Mycobacterium marinum.

[46] Savvidis G (1984) Quantitative Untersuchungen über das Vorkommen von Enterobacteriaceaen aus dem Darm von Süsswasserfischen unter besonderer Berücksichtigung von Yersinia ruckeri, den atiologischen Agent der ERD (Enteric Redmauth Disease) IneuguralDissertation, Hannover.

[47] Scales, BS., Erb-Downward, JR., Huffnagle, IM., LiPuma JJ, Huffnagle GB (2015). Draft Genome Sequences of Seven Pseudomonas fluorescens Subclade III Strains Isolated from Cystic Fibrosis Patients. Genome Announc. 3(1), e01285-14

[48] Seidel G.,Kiesewalter,J. (1992) Bakterielle Lebensmit telinfektionen- und intoxikationen, Akademie Verlag, Berlin(1992).

[49] Sinell H.J. (1985). Einführung in die Lebensmittelhygiene, Verlag Paul Parey.

[50] Stock I, (2004). Plesiomonas shigelloides: an emerging pathogen with unusual properties. Rev Med Microbiol. 15, 129-139.

[51] Souza, M. J. (2009) Bacterial and Parasitic Zoonoses of Exotic Pets. Veterinary Clinics: Exotic Animal Practice 12(3):401 - 415.

[52] Tandan N, Maini R, Al-Akchar M, Chua MF, Waqar S.A. (2020). Tale of strange bioprosthetic valve endocarditis: an uncommon presentation of mitral valve endocarditis with lactococcus garvieae acc march 24, 2020 volume 75, issue 11 . 
[53] Walton, RN., Clemens, A., Chung, J., Moore, S., Wharton, D., Haydu, L., De Villa E., Sanders,. G, Bussey J, Richardson., D, Austin JW. (2014). Outbreak of type E foodborne botulism linked to traditionally prepared salted fish in Ontario, Canada. Foodborne Pathog Dis. 11(10), 830-834.

[54] Weinstein, MR., Litt, M., Kertesz, DA., Wyper, P., Rose, D., Coulter, M., McGeer, A., Facklam R, Ostach C., Willey BM, Borczyk., A, Low DE (1997). Invasive infections due to a fish pathogen, Streptococcus iniae. N Engl J Med. 337, 589-94.

[55] Wijesinghe. RU., Oster, RJ., Haack, SK., Fogarty, LR., Tucker, TR., Riley, SC. (2015). Spatial, temporal, and matrix variability of Clostridium botulinum Type E toxin gene distribution at great lakes beaches. Appl Environ Microbiol. 81(13), 4306-4315.

[56] Uner, MC., Hascelik, G., Mustak, HK. (2016). 16S rRNA gen dizi analizi ile tanımlanan klinik Nocardia izolatlarının antimikrobiyal duyarlılıkları. Mikrobiyol Bul. 50(1), 11-20.

[57] Velayati AA., Rahideh S., Nezhad ZD., Farnia P., Mirsaeidi M. (2015). Nontuberculous mycobacteria in Middle East: Current situation and future challenges. Int J Mycobacteriol. 4(1), 7-17. 